\title{
Biodiesel Derive Bio-oil of Hermetia illucens Pre-pupae Catalysed by Sulphonated Biochar
}

\author{
Siew Yoong Leong ${ }^{1 *}$, Soo Shin Chong ${ }^{1}$, and Kah Seng Chin ${ }^{1}$ \\ ${ }^{1}$ Department of Petrochemical Engineering, Faculty of Engineering and Green Technology, \\ University of Tunku Abdul Rahman, Jalan Universiti, Bandar Barat, 31900 Kampar, Perak
}

\begin{abstract}
This study investigates the development of biochar catalyst from bamboo applied for biodiesel synthesis. A non-conventional biodiesel feedstock was used in the in-situ transesterification reaction. This nonconventional feedstock is obtained from an insect's fly, the Hermetia illucens fly. Biochar derived from bamboo has been investigated as a promising catalyst for biodiesel synthesis. The biochar acid catalysts were prepared by sulphonation via impregnation with concentrated sulphuric acid. The prepared catalysts were investigated for their performance to catalyse in-situ transesterification via ultra-sonication of Hermetia illucens bio-oil. The effects of carbonisation time (1 hour and 2 hour) and temperature $\left(400^{\circ} \mathrm{C}, 500^{\circ} \mathrm{C}\right.$ and $\left.600^{\circ} \mathrm{C}\right)$ as well as catalyst loading $(5-20$ wt $\%$ on oil basis) on the transesterification yield were studied. Result showed that the highest yield of FAME obtained was $95.6 \%$ with catalyst loading of $15 \mathrm{wt} \%$ carbonized at $500^{\circ} \mathrm{C}$ for 2 hours. Sharp band of methyl ester functional groups were observed in the FTIR spectra at 1735$1750 \mathrm{~cm}^{-1}$. The composition of this methyl ester was further deduced using gas chromatography and the fatty acid was predominantly lauric acid.
\end{abstract}

\section{Introduction}

Chemically, biodiesel is also known as fatty acids of mono alkyl ester [1-3]. Biodiesel is produced via transesterification reaction with a suitable catalyst either homogeneous [3] or heterogeneous [4]. The choice of catalyst selection is influenced by the amount of free fatty acids (FFA) presence in the feedstock. Homogeneous catalysts have always been the choice of catalyst for biodiesel production in large-scale operation. However, there are some shortcomings of using homogeneous catalyst due to non-recovery of the catalyst; poor thermal stability and require excessive of purification [5].

On the contrary, heterogeneous catalysts are capable to overcome the problems faced by the former ones. However, they were mostly derived from non-renewable resources and are expensive [6-7]. Recently, carbon based catalysts derived from agriculture waste have gained the attention from various researchers [6,8,10]. This type of catalysts offers numerous advantages, including renewable resources, non-toxic, reusable and reproducible, high catalytic activity, and stability in both acidic and basic conditions [2].

\footnotetext{
* Corresponding author: leongsy@utar.edu.my
} 
Carbon based catalyst were derived from various sources such as from palm waste [8], carbohydrates [9], coconut shell [10] and coffee grounds [11]. Past study showed that, sulfonated biochar catalyst has been used to for free fatty acid (FFA) esterification and transesterification of vegetable oil due to higher catalytic activity [6,9,12-13]. Lou [9] reported that, carbohydrate-derived catalysts for both esterification and transesterification have markedly enhanced the yield of methyl esters in converting waste cooking oils containing $27.8 \mathrm{wt} \%$ high free fatty acids (FFAs) into biodiesel. Study by Kastner [12], shows that, the conversion from esterification of the fatty acids was attained approximately at $\sim 90-100 \%$ conversion within $30-60 \mathrm{~min}$ at $55-60^{\circ} \mathrm{C}$ in excess of methanol blends with vegetable oil and animal fat (5-15 wt.\% FFA). Buasri [13] also carried out similar study on transesterification of waste frying oil (WFO) with methanol using potassium hydroxide catalyst supported on Jatropha curcas fruit shell activated carbon (KOH/JS). Approximately, $86.7 \%$ of the conversion yield was achieved with optimum conditions at reaction temperature of $60^{\circ} \mathrm{C}$ for $2 \mathrm{~h}$ with methanol/oil molar ratio of 16 and catalyst bed height of $250 \mathrm{~mm}$.

To the best of our knowledge, the utilization of carbon-based solid acid catalyst to synthesize biodiesel is mainly dedicated on the esterification reaction of FFA [12], edible oil, non-edible oil [14] and waste vegetable oil $[8,13]$. Based on our literature findings, the use of bamboo biochar catalyst to prepare biodiesel from the insect's bio-oils has not been reported so far. Therefore, the gap of this study has to be filled in order to develop a better understanding on the effect of the biochar catalyst towards biodiesel yield from our nonconventional feedstock (Hermetia illucens pre-pupae). In this study, bamboo biochar is chosen as the catalyst support due to chemically inert, inexpensive and naturally porous. Moreover, the morphological structure and physicochemical properties of biochar can be customised by altering the nature of biomass via pyrolytic conditions and/or treating biomass biochar [15]. The objective of this study is to develop low-cost, carbon-based acid catalyst from bamboo and to investigate the potential application of the catalyst for biodiesel production from Hermetia illucens pre-pupae bio-oil.

\section{Methodology}

\subsection{Catalyst preparation}

First phase is to develop the biochar catalyst using bamboo as heterogeneous catalyst. The biochar catalysts were prepared in a series of carbonization time ( 1 and $2 \mathrm{~h}$ ) and temperature $\left(400,500\right.$ and $\left.600^{\circ} \mathrm{C}\right)$. Subsequently, the biochars were sulphonated with concentrated sulphuric acid for $24 \mathrm{~h}$, filtered and washed with distilled water. The sulphonated biochars were dried in an oven for $24 \mathrm{~h}$ at $80^{\circ} \mathrm{C}$. The sulphonated biochar is denoted as $\mathrm{SB} x \_y \_z$ (e.g: $\left.\mathrm{SB} 400 \_1 \_5\right)$, where $x$ is carbonisation temperature $\left({ }^{\circ} \mathrm{C}\right), y$ is carbonisation time ( $\mathrm{min})$ and $z$ is catalyst loading $(\mathrm{wt} \%)$.

\subsection{In-situ transesterification via ultrasonication}

Second phase is the in-situ transesterification of fatty acid methyl ester (FAME) via ultrasonication using the prepared catalyst. Approximately, $5 \mathrm{~g}$ of dried Hermetia illucens pre-pupae was dispensed into a reaction vessel containing methanol, biochar catalyst and nhexane. Reaction parameters were fixed at $55^{\circ} \mathrm{C}$ for 248 min using 8:1 methanol to mass ratio at different catalyst loading of 5, 10, 15 and $20 \mathrm{wt} \%$ carbonized at different time and temperature. Prior analysis, sample FAME obtained was separated via centrifugation and was washed with distilled water at $70^{\circ} \mathrm{C}$. The experiments were conducted in triplicates. 


\subsection{Characterisation of biochar catalyst and FAME}

The morphologies of the sulfonated biochars were carried out using SEM with accelerating voltage of $2.0 \mathrm{kV}$, working distance of $6.4 \mathrm{~mm}$ and magnification of X1000. To qualitative assess, FTIR analysis was performed on the unsulphonate and sulphonated biochar catalyst. The biochar sample was finely grinded along with $\mathrm{KBr}$ IR grade using an agate mortar and pastel. The grinded sample was pressed into a disk and was placed at sample holder. The determination of FAME functional group was carried out using Fourier transform infrared (FTIR) equipped with attenuated total reflectance (ATR). Spectra were scanned over a wavenumber range of $4000-650 \mathrm{~cm}^{-1}$ at a resolution of $4 \mathrm{~cm}^{-1}$.

Analysis of FAME compositions were done in triplicates and determined using gas chromatography (GC) equipped with a capillary column, BPX 70. The compositions of FAMEs were compared with a standard, Supelco ${ }^{\circledR} 37$ Component FAME Mix purchased from Sigma Aldrich. The yield of FAME obtained was calculated according to Eq. (1).

$$
\text { Yield of FAME, } \%=\left(\frac{\text { masss of FAME }(\mathrm{g})}{\text { mass of oil }(\mathrm{g})} \times 100 \%\right)
$$

The total acid density of the sulphonated catalysts was determined using the standard acid-base back-titration method. The back titration was done by titrating $0.02 \mathrm{M}$ of $\mathrm{HCl}$ on $0.10 \mathrm{~g}$ of catalyst suspended into $60 \mathrm{~mL}$ of $0.01 \mathrm{M} \mathrm{NaOH}$.

\section{Results and discussions}

\subsection{Effect of carbonization time \& temperature on the sulphonated biochar morphology}

Morphology of the sulphonated biochar catalysts is illustrated in Fig. 1 and Fig. 2. As observed, the overall morphologies exhibit a porous structure, indicating the porosity was developed along with the increasing carbonization time and temperature. Furthermore, thicker cell walls were observed when the biochar was carbonised at 400 and $500^{\circ} \mathrm{C} \mathrm{(Fig.} 1$ and 2). The development of the pore size increases when the biochars were carbonised at $600^{\circ} \mathrm{C}$ as compared to those carbonised at 400 and $500^{\circ} \mathrm{C}$ (Fig. 1 and 2). However, as the carbonisation temperature and time increases, the pores structure showed greater destruction (Fig. 1c). This phenomenon is due to prolong heat treatment that leads to decomposition of bamboo mass and subsequently weakens the matrix structure in bamboo vascular.

The morphology shown in Fig. 1(c) exhibits rougher surface and irregular pores patterns as compared to the morphologies in Fig. 1 (a) and (b). This phenomenon is due to the devolatilisation of volatile matter occurs with increase in temperature causes the destruction of globular structure that presence inside the biochar. Similar phenomenon was also reported by Huang et al. [16].

Pore cracks were observed in Fig. 2(a) due to the damaged of the adjacent wall between the micropores to form mesopores and macropores at high temperature. Thangarajan et al., (2015) [17], also reported a similar finding. Moreover, pore cracks are an indication to a reduction in pore volume. Furthermore, mixtures of large pore and small pores were observed when the carbonisation temperature increases (Fig. 2 c). 


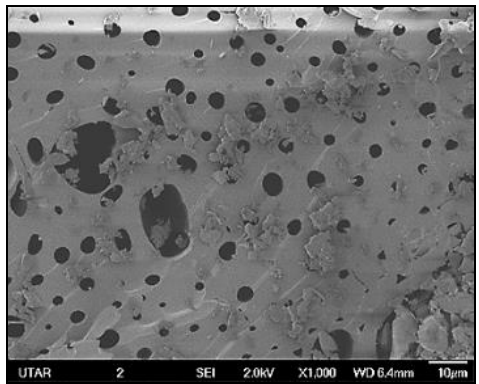

(a)

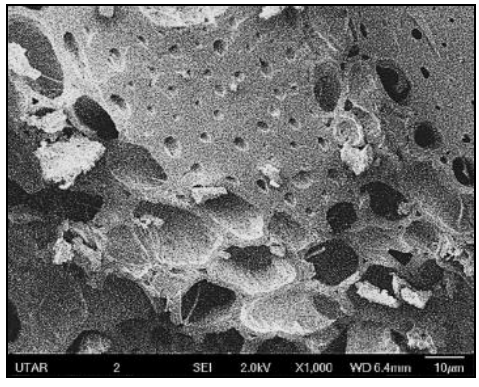

(b)

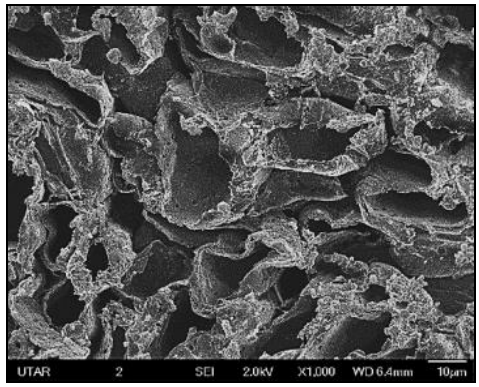

(c)

Fig. 1. SEM images for biochar carbonised at (a) $400^{\circ} \mathrm{C}$, (b) $500^{\circ} \mathrm{C}$ and (c) $600^{\circ} \mathrm{C}$ for $1 \mathrm{~h}$.

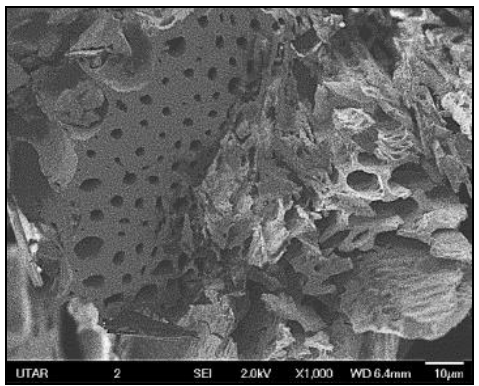

(a)

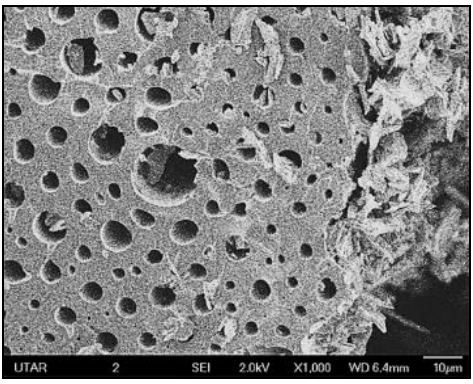

(b)

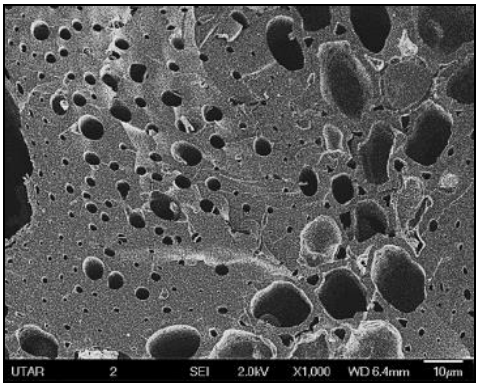

(c)

Fig. 2. SEM images for biochar carbonised at (a) $400^{\circ} \mathrm{C}$, (b) $500^{\circ} \mathrm{C}$ and (c) $600^{\circ} \mathrm{C}$ for $2 \mathrm{~h}$.

\subsection{Effect of catalytic activity on FAME yield}

In this study, in-situ transesterification of FME was carried out using the Hermetia illucens pre-pupae biomass. The reaction conditions were fixed at $55^{\circ} \mathrm{C}$ with $5.8: 1$ of methanol to mass ratio for 248 mins. The effects of the catalytic activity were studied for the carbonization time and temperatures as well as catalyst loading. Fig. 3 illustrates the yield of FAME obtained with various parameters. 


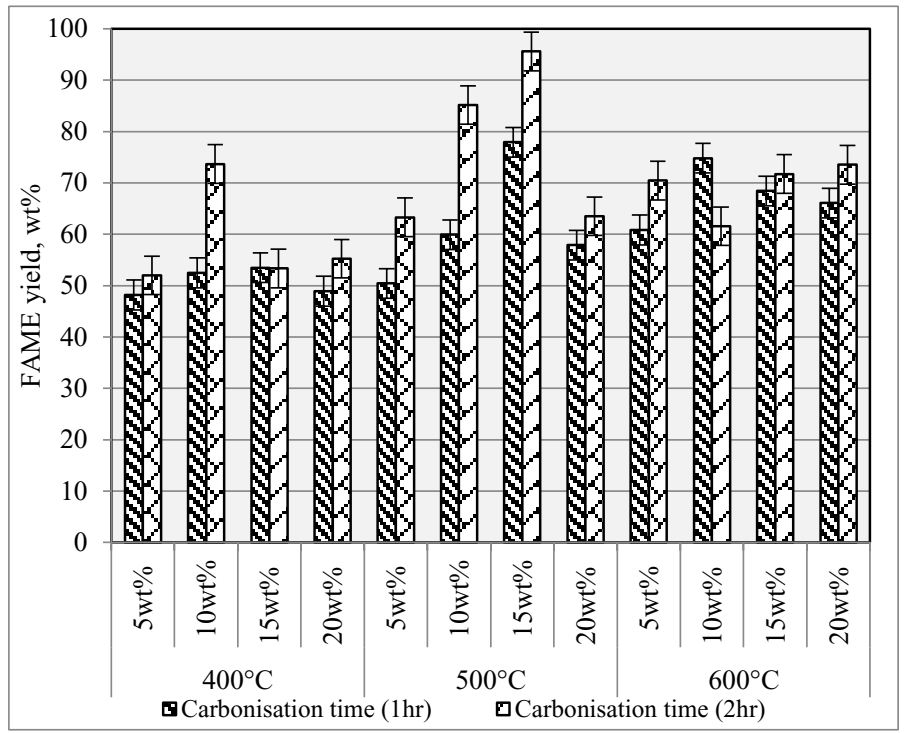

Fig. 3. The yield of FAME obtained with various catalyst loading and carbonisation parameters.

The results obtained indicated that the catalyst loading plays an important role in catalytic performance for FAME production. In general, the yield of FAME increases along with the increase of catalyst loading from 5 to $15 \mathrm{wt} \%$. Further increase of catalyst loading from $15 \mathrm{wt} \%$ up to $20 \mathrm{wt} \%$ will lead to a decreases in yield. This trend was observed for catalysts carbonised at 1 hour for 400,500 and $600^{\circ} \mathrm{C}$, respectively. Furthermore, catalytic performances of FAME yield were also affected by carbonisation time and temperature. This is evident for carbonization at 400 and $500^{\circ} \mathrm{C}$, showing a rising trend in FAME yield from 1 to 2 hour, respectively. However, the catalytic activity decreases with further increased in carbonisation temperature to $600^{\circ} \mathrm{C}$. The performances of the catalyst at $600^{\circ} \mathrm{C}$ did not show much improvement on the yield production $(60.84-74.82 \mathrm{wt} \%)$ with effect of time and catalyst loading. Conversions of FAME at this temperature had negatively influenced the FAME yield. The catalytic activities at this point were drastically decreasing than that of $500^{\circ} \mathrm{C}$.

The catalytic performance showed higher yield with longer carbonization duration for 400 and $500^{\circ} \mathrm{C}$. Highest catalytic performances were better at $2 \mathrm{~h}$ of carbonisation than that of $1 \mathrm{~h}$. The highest yield obtained was attained at $95.6 \mathrm{wt} \%$ for reaction with SB500_2_15 catalyst with $4.007 \mathrm{mmol} / \mathrm{g}$ total $-\mathrm{SO}_{3} \mathrm{H}$ acid density (Fig. 4). Increase in yield is attributed to the morphological structure that is better pore development and therefore increases the probabilities of the acid group attachment. The increasing time and temperature during carbonisation have led to the decrease in carbon sheets and destruction of pores structure thus resulting lower FAME yield. Subsequently, lessens $\mathrm{SO}_{3} \mathrm{H}$ actives site catalysts attachment on the biochar. The poor performance is evidence from Fig. 4 depicting the low acid site ranging from $2.01-2.21 \mathrm{mmol} / \mathrm{g}$. Hence, this explains the poor catalytic performances at $600^{\circ} \mathrm{C}$. Moreover, high catalyst loading effect negatively on the yield due to ether formation generated from the excess of acid [18]. Besides that, emulsifications occurred when excess of catalyst loading is applied and in the long run affects the separation between FAME and by product. Hence, this is also another reason leading to lower FAME yield. 


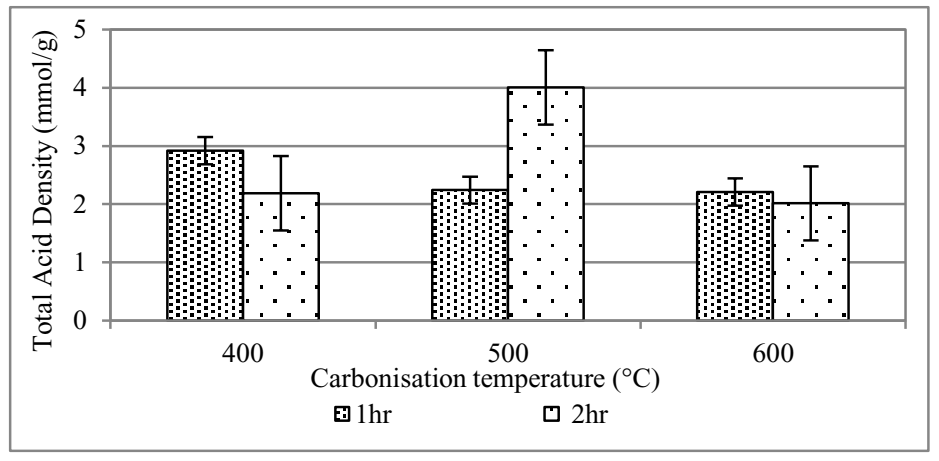

Fig. 4. Total acid density $\left(-\mathrm{SO}_{3} \mathrm{H}\right)$ of the sulphonated biochar catalyst.

\subsection{Analysis of functional group for FAME and biochar catalyst}

Fig. 5 compares the characteristics of functional group between the sample and standard FAME. As observed, both FTIR spectra shows the presence of strong stretching carbonyl group $(\mathrm{C}=\mathrm{O})$ at $1746.9 \mathrm{~cm}^{-1}$ and that confirms the presence of mono alkyl esters. Furthermore, bending vibrations of $\mathrm{CH}_{2}$ and $\mathrm{CH}_{3}$ aliphatic groups was detected in both FAME and the standard at absorption band of $1449.36 \mathrm{~cm}^{-1}$. Absorption bands observed at 2921.68 and $2855.45 \mathrm{~cm}^{-1}$ were attributed by asymmetric and symmetric vibration of aliphatic $-\mathrm{CH}_{2}$ fatty acids hydrocarbon chains, respectively. The bands at 721 and 862.65 $\mathrm{cm}^{-1}$ showed the $\mathrm{CH}_{2}$ rocking out-of-plane vibration. The FTIR spectrum in Figure 5 confirms that the identified functional groups in the FAME were also perceived in the standard.

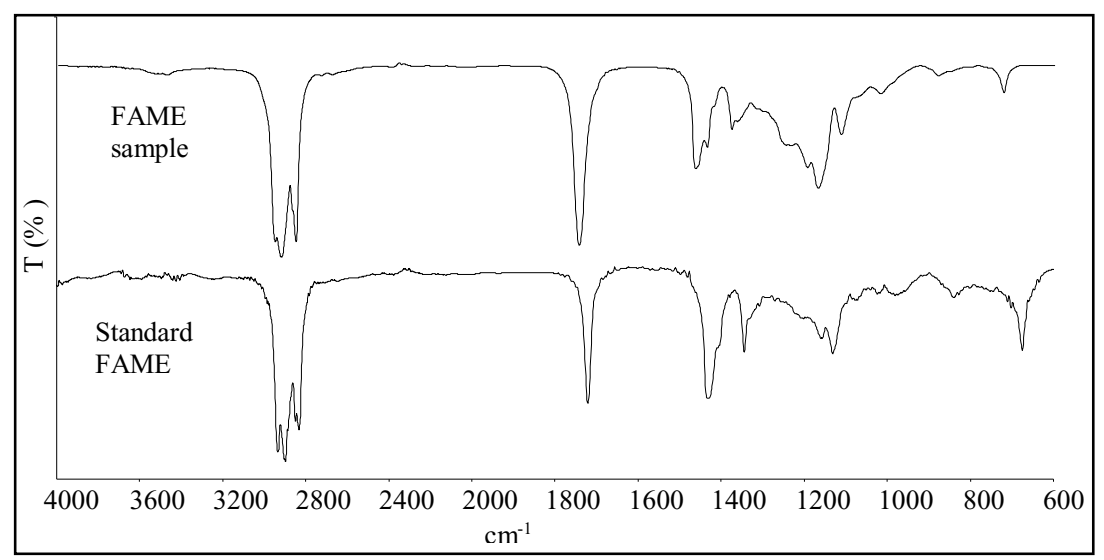

Fig. 5. FTIR spectra of FAME. 


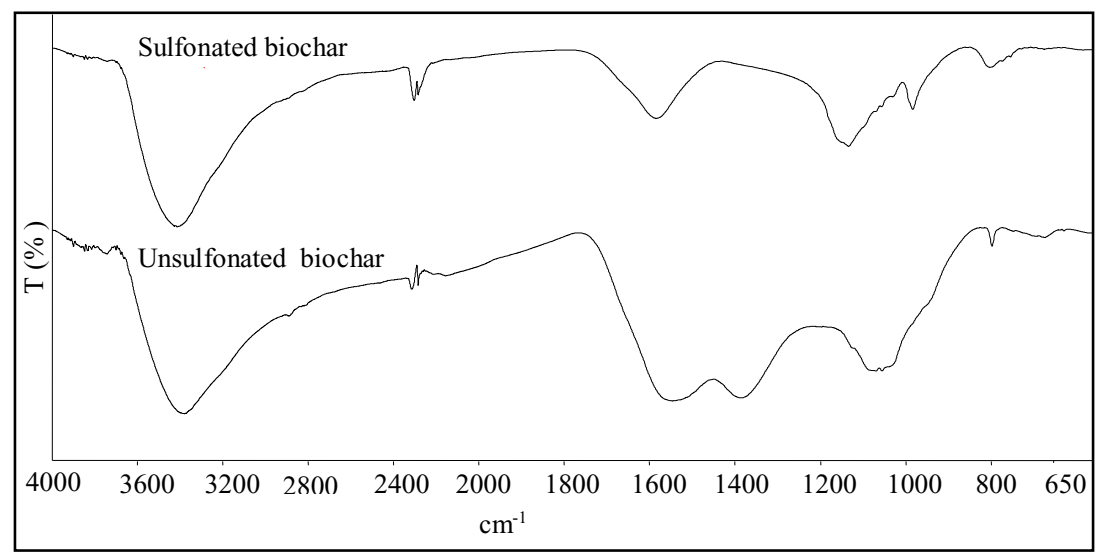

Fig. 6. FTIR for (a) unsulphonated and (b) sulphonated bamboo biochar.

Fig. 6 compares surface functional groups between unsulphonated and sulphonated biochar catalyst. The FTIR spectrum of sulphonated biochar shows a strong $\mathrm{C}-\mathrm{H}$ bending at $880 \mathrm{~cm}^{-1}$ that attributed to 1,2,4-trisubstituted ring of aromatic and heteroatomic compounds. The band $1442 \mathrm{~cm}^{-1}$ is attributable to medium stretch of $\mathrm{C}-\mathrm{C}$ aromatic compounds found in the unsulphonated biochar. This band disappeared after sulphonation indicating cellulose chain continues to convert into polycyclic aromatic hydrocarbon structure during sulphonation. The absorption bands between $780-850 \mathrm{~cm}^{-1}$ indicates the out of plane bending in the unsulphonated biochar. The band at 1200 and $1055 \mathrm{~cm}^{-1}$ specifies a strong $\mathrm{S}=\mathrm{O}$ stretching of sulphate and sulphoxide functional groups. However, these two bands were not observed in the unsulphonated biochar. This indicates the presence of $\mathrm{SO}_{3} \mathrm{H}$ groups, by this means confirming the incorporation of sulphonic groups onto the biochar matrix. Both samples in $1650-1566 \mathrm{~cm}^{-1}$ were a group of $\mathrm{C}=\mathrm{C}$ medium stretching vibration peak, which may attribute to cyclic alkene, monosubstituted and disubstituted (cis) alkene [19]. All samples also indicate a broad $\mathrm{O}-\mathrm{H}$ bending between $3550-3200 \mathrm{~cm}^{-1}$ indicating the presence of oxygen containing functional groups such as phenolic hydroxyl and carboxylic groups in polycyclic aromatic skeleton.

\section{Conclusions}

In conclusion, the development of sulphonated biochar catalyst has successfully shown the catalytic ability to produce FAME. Significant effect on the catalytic activity of the sulphonated biochar catalyst was displayed by SB500_2_15. This catalyst showed the highest catalytic performance as evidence from the yield of FAME which attained at 95.6 $\mathrm{wt} \%$. However, the catalytic activity did not give rise to FAME yield when the catalyst was carbonised at $600^{\circ} \mathrm{C}$. This is due to the decrease in carbon sheets and destruction of pores structure at $600^{\circ} \mathrm{C}$. Hence, makes the attachment of sulfonic group more difficult and eventually results in lower FAME yield. The catalyst derived from bamboo in this study has shown a promising application as a solid acid catalyst for biodiesel production.

The authors would like to thank the University of Tunku Abdul Rahman (UTAR) for the laboratory facilities.

\section{References}

1. L.J. Konwar, J. Boro, D. Deka, Renew. \& Sus.t Energ. Rev. 29, 546-564 (2014) 
2. A.P.S. Chouhan, A.K. Sarma, Renew. \& Sust. Energ. Rev. 15, 4378-4399 (2011)

3. A. Demirbas. Int. J. of Green Energ. 4, 15-26 (2007)

4. R. Ormsby, J.R. Kastner, J. Miller, Catal. Today 190, 89-97 (2012).

5. Y. Zhang, M.A. Dube, D.D. McLean, M. Kates, Bioresour. Technol. 89, 1-16 (2003)

6. A.M. Dehkhoda et al. Appl. Catal. A: General 382, 197-204 (2010)

7. D.E. López, J. Goodwin, D.A. Bruce, E. Lotero, Appl. Catal. B 295, 97-105 (2005)

8. Q. Shu, J. Gao, Z. Nawaz, Y. Liao, D. Wang, J. Wang, Appl. Energ. 87, 2589-2596 (2010)

9. W.Y. Lou, M. H Zong, Z.Q Duan, Bioresour. Technol 99, 8752-8758 (2008)

10. Y.M. Sani, A.O. Raji, P.A. Alaba, Bioresour. 10, 3393-3408 (2015)

11. D.R. Vardon, B.R. Moser, W. Zheng, K. Witkin, R.L. Evangelista, ACS Sustainable Chem. Eng. 1, 1286-1294 (2013)

12. J.R. Kastner, J. Miller, D.P. Geller, J. Locklin, L.H. Keith, T. Johnson, Catal. Today 90, $122-132$ (2012)

13. A. Buasri, N. Chaiyut, V. Loryuenyong, C. Rodklum, T. Chaikwan, N. Kumphan, Appl. Sci. 2, 641 - 653 (2012)

14. F. Pua, Z. Fang, S. Zakaria, F. Guo, C. Chia, Biotech. for Biofuels 4, 1 - 8 (2011)

15. A.U. Rajapaksha., S.S. Chen., D.C.W. Tsang., M. Zhang., M. Vithanage., S. Mandal., B. Gao., N.S. Bolan., Y.S. Ok. Chemosphere 148, 276-291 (2016)

16. P. Huang, J. Jhan, Y. Cheng, H. Cheng. The Scientific World Journal; 1 - 8 (2014)

17. R. Thangarajan, N. Bolan, S. Mandal, A. Kunhikrishnan, G. Choppala, et al (2015). Biochar for inorganic contaminant management in soil (Chapter 5): 'Biochar: Production, Characterization and Applications' (Eds. Ok Yong Sik, Uchimiya Minori, Chang Scott and Nanthi Bolan). Pages 99-138; FL, USA: CRC Press, ISBN1482242303, 9781482242300.

18. J. Emrani and A. Shahbazi, Journal of Biotech. \& Biomat. 2, 124 (2012)

19. S.Y. Ouyang, K. Xiangming, X. Qiong, Y. Dulin, Journal of Mat. Sci. \& Chem. Eng. 2, $4-8$ (2014) 